\title{
Analisis Pressure Drop pada Jaringan Pipa Pelanggan Biogas di TPA Supiturang Kota Malang
}

\author{
Gigis Kintan Miyarthaluna, Ridho Hantoro \\ Teknik Fisika, Fakultas Teknik Industri, Institut Teknologi Sepuluh Nopember (ITS) \\ e-mail: gigis.kintan.m@gmail.com, hantoro@ep.its.ac.id
}

\begin{abstract}
Abstrak-Pressure drop merupakan salah satu permasalahan yang dihadapi oleh jaringan pipa pelanggan biogas di TPA Supiturang. Penambahan 80 pelanggan baru akan meningkatkan pressure drop sehingga tekanan biogas menuju ke kompor menurun. Sedangkan, tekanan optimun biogas dan landfill gas menuju kompor sebesar 1,0 kPa. Pada penelitian ini dilakukan perhitungan pressure drop jaringan pipa pelanggan biogas existing dan future. Jaringan pipa future pada branch $\mathrm{XA}, \mathrm{XB}$, dan XC terdapat delapan variasi model, yaitu antara lain model A1, A2, A3, A4, B1, B2, B3, dan B4. Hasil perhitungan jaringan pipa existing menunjukkan error hasil perhitungan kurang dari 3\%. Tekanan biogas menuju ke kompor telah memenuhi minimun pressure. Hasil perhitungan jaringan pipa future pada branch XB dan XC menunjukkan bahwa tekanan tertinggi dihasilkan model A1. Pada branch XA, tekanan tertinggi dihasilkan model A2. Hal ini terjadi karena friction loss lebih kecil pada branch $\mathrm{XB}$ dan $\mathrm{XC}$ dengan model A1. Sedangkan pada branch XA, model A2 memiliki debit terkecil. Maka model A1 digunakan sebagai desain pada jaringan pipa future.
\end{abstract}

Kata Kunci-Biogas, headloss, pipa, pressure drop.

\section{PENDAHULUAN}

$\mathrm{M}$ ALANG merupakan kota dengan populasi 894.653 penduduk dan menghasilkan municipal solid waste (MSW) sebesar 660 ton per hari dengan laju perningkatan MSW mencapai $10 \%$ dari total MSW. Permasalahan MSW merupakan permasalahan yang serius. Sistem pengelolaan MSW yang masih open dump berpotensi bahaya. Dekomposisi MSW menghasilkan biogas yang mengandung karbondioksida dan metana. Gas metana yang tidak dikontrol dan terkonsentrasi akan menyebabkan ledakan seperti yang terjadi di TPA Leuwigajah [1]. Padahal gas metana yang dihasilkan dapat dimanfaatkan sebagai energi terbarukan yaitu sebagai bahan bakar pengganti LPG. Pada tahun 2009, kebutuhan LPG di sektor rumah tangga kira-kira 7,44\% dari total energi yang dimiliki Indonesia [2]. Upaya penurunan konsumsi LPG di sektor rumah tangga dapat dilakukan dengan memanfaatkan gas metana yang dihasilkan di landfill.

Pemerintah Kota Malang telah mencanangkan beberapa program untuk mengatasi permasalahan ini. Salah satunya yaitu penerapan sistem control landfill di TPA Supiturang. Penerapan sistem control landfill ini sesuai dengan penerapan Undang-Undang Pengelolaan Sampah No. 18 Tahun 2008 yang menyatakan bahwa penimbunan sampah di Tempat Pemrosesan Akhir Sampah dilakukan secara terkendali dengan sistem control landfill / sanitary landfill [3]. Gas metana yang dihasilkan kemudian disalurkan ke masyarakat sebagai energi altenatif.

TPA Supiturang berlokasi di Kelurahan Mulyorejo, Kota Malang. Luas kawasan mencapai 31 hektar dan volume sampah 420,48 ton/hari dengan sistem control landfill. Komposisi MSW yaitu 70,5\% organik dan 29,5\% anorganik [4]. Septiropa dkk (2011) meneliti sudut ujung pipa penangkapan optimal gas metana di TPA Supiturang. Kedalaman dan sudut optimal dari pipa ekstraksi vertikal dihitung. Penelitian ini mendapatkan bahwa kedalaman maksimal yang dapat dijangkau yaitu $520 \mathrm{~cm}$ dan sudut $30^{\circ}$ dianggap paling optimal [5].

Pada tahun 2012, berdasarkan hasil perhitungan GIZ VNAMAs potensi gas metana mencapai 4.521 ton/tahun. Pada tahun 2013, Sambungan Rumah (SR) mencapai 300. Namun, potensi gas metana masih belum optimal. Pada tahun 2014, Rahajeng dkk menemukan bahwa pemanfaatan gas metana hanya $0,013 \%$ dari potensi gas yang ada. Peningkatan perlu dilakukan sehingga potensi gas metana dapat dioptimalkan [6]. Pada tahun 2014, jumlah sumur penangkapan gas sebanyak enam puluh titik, panjang jaringan induk pipa gas $2.700 \mathrm{~m}$, dan sambungan rumah $408 \mathrm{SR}$. Jaringan dan penyaluran gas metana terdiri dari instalasi pengambilan gas metana, instalasi pemisah gas dan air, instalasi pengendalian gas, dan instalasi pelepasan gas flaring. Instalasi-instalasi tersebut dihubungkan dengan jaringan pipa [4]. Namun pada tahun 2015, terjadi penurunan pelanggan biogas sehingga hanya 196 pelanggan saja. Penurunan ini terjadi karena pelanggan tidak dapat menggunakan biogas dari jaringan pipa pelanggan biogas.

Permasalahan yang dihadapi instalasi gas metana yaitu pressure drop. Pressure drop mempengaruhi tekanan yang diterima kompor. Semakin besar pressure drop maka semakin kecil tekanan yang diterima kompor. Penelitian Grima-Olmedo dkk (2014) menunjukkan bahwa tekanan optimal LFG (landfill gas) untuk menghasilkan energetic performance terbesar yaitu 10 mbar [7].

Jaringan pipa pelanggan biogas melalui banyak fitting 
sehingga pressure drop yang dihasilkan menjadi besar. Penambahan konsumen baru akan meningkatan pressure drop. Hasil dari perhitungan akan menunjukkan apakah jaringan pipa pelanggan biogas existing dan future memiliki pressure drop besar. Pressure drop diatasi dengan pembuatan desain jaringan pipa baru. Desain jaringan pipa baru akan dihitung sehingga didapatkan pressure drop terkecil.

Berdasarkan penjelasan penjelasan diatas maka penelitian digunakan untuk mengetahui besar pressure drop pada jaringan pipa pelanggan biogas. Selain itu, untuk mengetahui hasil perhitungan pressure drop untuk pengembangan jaringan pipa pelanggan biogas.

\section{METODELOGI PENELITIAN}

\section{A. Pengambilan Data}

\section{1) Persiapan Alat dan Bahan}

Alat dan bahan yang dipersiapkan yaitu antara lain manometer, pipa Wavin AW ukuran $1 / 2$ ", tee Wavin AW ukuran 1/2", elbow Wavin AW ukuran 1/2", dan nipple ukuran $3 / 4$ ".

\section{2) Pengukuran Debit Landfill Gas}

Pengukuran debit dilakukan dengan pembacaan meteran gas yang sudah ada. Pengukuran dilakukan setiap satu jam atau dua jam. Debit LFG dirumuskan dengan (1)

$$
Q=\frac{\Delta V o l}{\Delta t}
$$

dimana $\triangle V o l$ adalah selisih volume LFG yang dari hasil pembacaan metering gas $\left(\mathrm{m}^{3}\right)$ dan $\Delta t$ adalah lama waktu pengamatan (detik).

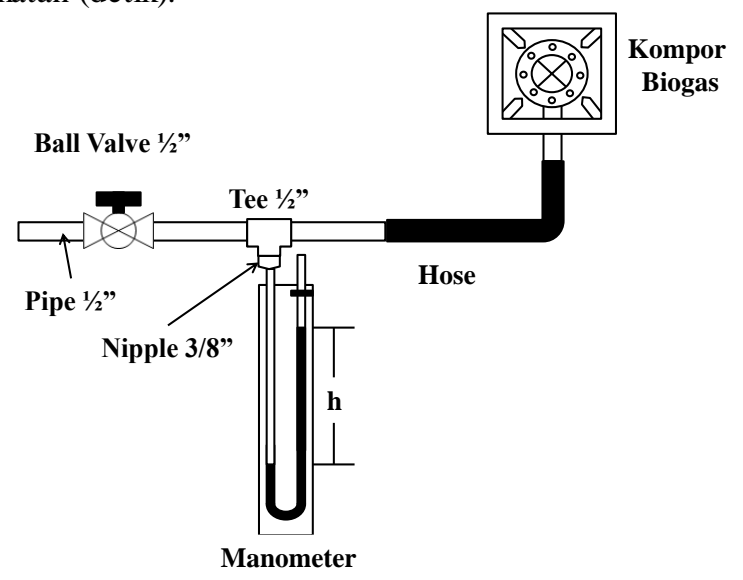

Gambar 1. Konfigurasi pemasangan manometer di RK1, RK2, dan RK3.

\section{3) Pengukuran Tekanan di Rumah Kontrol}

Tekanan biogas didapatkan dengan pengukuran menggunakan manometer air dengan ujung tertutup. Manometer dipasang sesuai dengan Gambar 1. Manometer dipasang pada tiga rumah kontrol (RK) yaitu RK1 (RT 5), RK2 (RT 7) dan RK3 (RT 4). Pengukuran dilakukan ketika ball valve dibuka setiap satu jam atau dua jam.

Tekanan absolut dirumuskan dengan menggunakan (2)

$$
P_{A}=P_{0}+\gamma h
$$

dimana $P_{A}$ adalah tekanan di rumah kontrol (Pascal), $P_{0}$ adalah tekanan atmosfir (101325Pascal), $\gamma$ adalah spesific grafity air, dan $h$ adalah selisih ketinggian air di manometer (m). Pengukuran temperatur lingkungan dan biogas dilakukan sekali. Data hasil pengukuran temperatur dan tekanan digunakan untuk menghitung properties LFG.

\section{B. Perhitungan Properties LFG}

Perhitungan properties LFG menggunakan asumsi bahwa LFG tidak mengalami pretreatment untuk meningkatkan kadar $\mathrm{CH}_{4}$ sehingga digunakan nilai standard komposisi LFG. Fraksi mol $\mathrm{CH}_{4}$ dan $\mathrm{CO}_{2}$ diasumsikan sebesar 0,5 dan 0,5.

Berdasarkan Densitas LFG pada tekanan tertentu dirumuskan dengan (3)

$$
\rho=\rho^{0} \frac{P}{P^{0}}
$$

dimana $\rho$ adalah densitas $\mathrm{LFG}\left(\mathrm{kg} / \mathrm{m}^{3}\right), \rho^{0}$ adalah densitas LFG refrensi $\left(\mathrm{kg} / \mathrm{m}^{3}\right), P^{0}$ adalah tekanan refrensi $(\mathrm{Pa})$, dan $P$ adalah tekanan gas $(\mathrm{Pa}) . \rho^{0}$ yaitu sebesar $1,26 \mathrm{~kg} / \mathrm{m}^{3}[8]$.

Berdasarkan [9], viskositas LFG dirumuskan dengan (4)

$$
\mu_{m}=\frac{\mu_{1} y_{1} \sqrt{M_{1}}+\mu_{2} y_{2} \sqrt{M_{2}}}{y_{1} \sqrt{M_{1}}+y_{2} \sqrt{M_{2}}}
$$

dimana $\mu$ adalah viscositas LFG (N.s/m²), $\mathrm{y}_{1}$ adalah mole fraction $\mathrm{CH}_{4}, \mu_{1}$ adalah viscositas $\mathrm{CH}_{4}$ (N.s $\left./ \mathrm{m}^{2}\right), M_{1}$ adalah molecular weight $\mathrm{CH}_{4}, y_{2}$ adalah mole fraction $\mathrm{CO}_{2}$, dan $\mu_{2}$ adalah viscositas $\mathrm{CO}_{2}$ (Pa.s), $M_{2}$ adalah molecular weight $\mathrm{CO}_{2}$.

Berdasarkan [10], viskositas $\mathrm{CH}_{4}$ dan $\mathrm{CO}_{2}$ pada temperatur tertentu dirumuskan dengan (5) dan (6)

$$
\begin{aligned}
& \mu_{C_{H_{4}}}=(1,935+0,0305 \Phi) \times 10^{-6} \\
& \mu_{\mathrm{CO}_{2}}=\left(-30,212+0,256 \Phi-0,00035 \Phi^{2}\right) \times 10^{-6}
\end{aligned}
$$

dimana $\Phi$ adalah temperatur gas (Kelvin).

\section{Perhitungan Pressure Drop}

Berdasarkan [12], aliran gas didalam pipa mengikuti Hukum Bernouli yang dirumuskan dengan (7)

$$
\frac{P_{1}}{\rho g}+\frac{\bar{V}_{1}^{2}}{2 g}+z_{1}=\frac{P_{2}}{\rho g}+\frac{\bar{V}_{2}^{2}}{2 g}+z_{2}+h_{l_{T}}
$$

dimana $P_{1}$ adalah tekanan upstream $(\mathrm{Pa}), P_{2}$ adalah tekanan downstream $(\mathrm{Pa}), \bar{V}_{1}$ adalah kecepatan rata-rata upstream $(\mathrm{m} / \mathrm{s}), \quad \bar{V}_{2}$ adalah kecepatan rata-rata downstream $(\mathrm{m} / \mathrm{s}), z$ adalah elevasi pipa (m), dan $h_{l T}$ adalah total headloss (m).

Total head loss adalah penjumlahan major loss dan minor loss, dirumuskan dengan (8).

$$
h_{l_{Y}}=h_{l}+h_{l_{m}}
$$


Tabel 1.

Spesifikasi pipa [13].

\begin{tabular}{ccccc}
\hline \hline Size & DO & $\mathrm{t}$ & $\mathrm{DI}$ & $\varepsilon / \mathrm{D}$ \\
\hline $1 / 2 "$ & 22 & 1,5 & 19 & $7,89474 \times 10^{-5}$ \\
1 & 32 & 2 & 28 & $5,35714 \times 10^{-5}$ \\
$11 / 4 ”$ & 42 & 2,3 & 37,4 & $4,0107 \times 10^{-5}$ \\
$2 "$ & 60 & 2,3 & 55,4 & $2,70758 \times 10^{-5}$ \\
\hline \hline
\end{tabular}

Tabel 2.

Coefficient loss pada berbagai fitting [12]

\begin{tabular}{llc}
\hline \hline & Component & $\mathrm{K}_{\mathrm{L}}$ \\
\hline Elbow & Regular $90^{\circ}$, threaded & 1,5 \\
& Long $90^{\circ}$, threaded & 0,7 \\
& Regular $45^{\circ}$, threaded & 0,4 \\
\hline Tee & Line flow, threaded & 0,9 \\
& Branch flow, threaded & 2,0 \\
\hline Reducting socket & 1 "x1/2" & 0,05 \\
& $11 / 4$ "x 1" & 0,07 \\
& 2"x1" & 0,07 \\
& 2"x11/4" & 0,06 \\
\hline Union, threaded & & 0,08 \\
\hline Valves & Ball valve, fully open & 0,05 \\
& Ball valve, $1 / 3$ closed & 5,5 \\
& Ball valve, ${ }^{2} / 3$ closed & 210 \\
\hline \hline
\end{tabular}

Major losess dirumuskan dengan (9)

$$
h_{l}=f \frac{L}{D} \frac{\bar{V}^{2}}{2 g}
$$

Minor lossess dirumuskan dengan (10) dan (11)

$$
\begin{aligned}
& h_{l_{m}}=K \frac{\bar{V}^{2}}{2 g} \\
& h_{l_{m}}=f \frac{L_{e}}{D} \frac{\bar{V}^{2}}{2 g}
\end{aligned}
$$

Pressure drop pada segment pipa dirumuskan dengan (12)

$$
\Delta P=\rho g h_{l_{T}}=\rho g\left(h_{l}+h_{l_{m}}\right)
$$

Persamaan (9) dan (10) disubtitusi ke (12) sehingga

$$
\Delta P=\rho\left[\frac{\bar{V}^{2}}{2}\left(f \frac{L}{D}+\sum K\right)\right]
$$

dimana $f$ adalah friction factor, $L$ adalah panjang pipa (m), $K$ adalah koefisien loss pada fitting yang ditunjukkan pada Tabel 2, dan Le adalah equivalenth lenght pipa (m). Kecepatan fluida dalam pipa dirumuskan dengan (14)

$$
V=\frac{Q}{A}=\frac{4 Q}{\pi D^{2}}
$$

dimana $Q$ adalah debit fluida $\left(\mathrm{m}^{3} / \mathrm{s}\right), A$ adalah cross sectional pipa $\left(\mathrm{m}^{2}\right)$, dan $D$ adalah diameter dalam pipa (m) yang ditunjukkan pada Tabel 1.

Friction factor tergantung dari jenis aliran fluida. Besar nilai
Re menentukan jenis aliran fluida. Jika $\operatorname{Re} \leq 2000$ maka aliran laminar. Jika 2000>Re<4000 maka aliran transisi. Sedangkan jika Re>4000 maka aliran turbulent.

Nilai Re dirumuskan dengan (15).

$$
\operatorname{Re}=\frac{V D \rho}{\mu}
$$

Friction factor didapatkan dengan (16) dan (17). Friction factor juga didapatkan dari Moody's Diagram dimana nilai $\varepsilon / D$ didapatkan dari Tabel 1.

$$
\begin{aligned}
& f=\frac{64}{\operatorname{Re}} \\
& f=\frac{0,3164}{\operatorname{Re}^{0,25}}
\end{aligned}
$$

Pipa dapat dipasang secara paralel dan seri. Pipa yang dipasang paralel akan mengalami pembagian aliran.

Rasio debit pada pipa yang dipasang paralel dirumuskan dengan (18). Debit pada branch dirumuskan dengan (19) dan (20)

$$
\begin{aligned}
& m=\frac{Q_{2}}{Q_{1}}=\left(\frac{L_{1}}{L_{2}}\right)^{0.5}\left(\frac{D_{2}}{D_{1}}\right)^{2.5} \\
& Q_{1}=\frac{1}{m+1} Q \\
& Q_{2}=\frac{m}{m+1} Q
\end{aligned}
$$

dimana $m$ adalah rasio debit, $Q_{l}$ adalah debit pada branch $1\left(\mathrm{~m}^{3}\right)$ dan $Q_{2}$ adalah debit pada branch $2\left(\mathrm{~m}^{3}\right)$.

\section{Penentuan Model Jaringan Pipa Future}

Desain jaringan pipa pelanggan biogas didapatkan dengan memanipulasi posisi branch dan model branch. Pressure drop pada setiap model dihitung sesuai dengan persamaan (17). Hasil perhitungan pada branch XA, XB, dan XC dengan model-model tersebut dibandingkan dan dipilih model dengan pressure downstream tertinggi.

Variasi branch XA, XB, dan XC terdairi dari delapan model yaitu A1, A2, A3, B1, B2, dan B3. A dan B menunjukkan model branch sedangkan 1, 2, 3, dan 4 menunjukkan posisi branch. Pada Model A1 dan B1, branch XB dan XC dicabang pada T. Sedangkan branch XA dicabang pada X. Pada Model A2 dan B2, posisi branch baru berada setelah branch X. Branch XA dicabang pada X. Sedangkan branch XB dan XC dicabang pada XA. Pada Model A3 dan B3, posisi branch baru di antara branch $\mathrm{T}$ dan V. Branch XA, XB dan XC dicabang sebelum V. Pada Model A4 dan B4, Posisi branch baru sesudah branch $\mathrm{T}$. Branch XA, XB dan XC dicabang dengan T. 


\section{ANALISIS DATA DAN PEMBAHASAN}

\section{A. Hasil Pengukuran Debit Landfill Gas}

Hasil pengukuran debit menunjukkan hasil yang fluktuatif, yang ditunjukkan pada Gambar 2. Pengukuran pada hari kedua tidak dapat dilakukan pada jam diatas 16:00 karena keterbatasan waktu. Debit biogas lebih kecil dari $2 \mathrm{~m}^{3} / \mathrm{h}$ dan nilainya fluktuatif. Pada hari pertama, debit terbesar terjadi pada pukul 16:00 dan debit terkecil pada pukul 10:00. Sedangkan pada hari kedua, debit terbesar terjadi pada pukul 08:00 dan terkecil terjadi pada pukul 15:00. Debit yang digunakan dalam perhitungan adalah debit rata-rata biogas yaitu sebesar $1.496346 \mathrm{~m}^{3} / \mathrm{h}$ atau $0,000415652 \mathrm{~m}^{3} / \mathrm{s}$.

Besarnya debit tergantung pada proses dekomposisi.

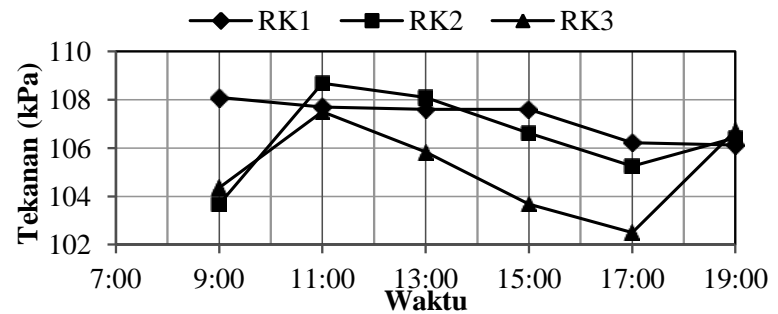

(a)

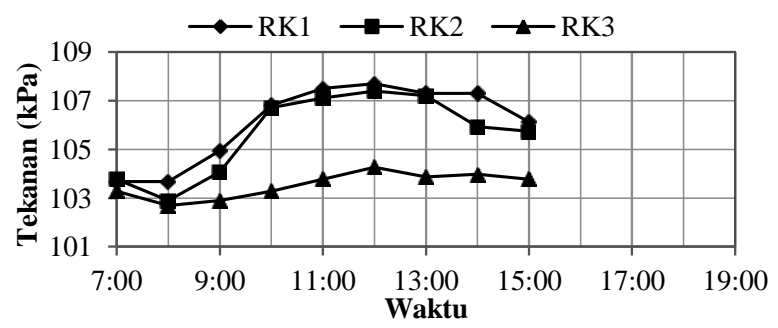

(b)

Gambar 3. Hasil pengukuran tekanan LFG di RK1, RK2, dan RK3 pada (a) hari pertama dan (b) hari kedua dalam $\mathrm{kPa}$.

Berdasarkan [11], proses dekomposisi untuk menghasilkan LFG dipengaruhi oleh sifat bahan mentah dan kondisi operasional selama reaksi anaerob seperti kelembaban, temperature, tingkat keasaman, kontur tanah, konsentrasi gas metana, oksigen, nutrisi, dan lain-lain . Keadaan cuaca pada saat penelitian adalah hujan pada hari pertama dan cerah pada hari kedua. Pada saat hujan maka ada penambahan kandungan air pada MSW sehingga meningkatkan produksi LFG.

\section{B. Hasil Pengukuran Tekanan di Rumah Kontrol}

Hasil pengukuran tekanan di RK (Rumah Kontrol) menunjukkan hasil yang fluktuatif, yang ditunjukkan pada Gambar 3a dan Gambar 3b. Tekanan tertinggi terjadi pada hari pertama sedangkan pada hari kedua tekanan menurun sangat besar di RK3.

Hal ini disebabkan oleh beberapa faktor. Faktor terbesar yaitu penggunaan pelanggan biogas. Pada hari kedua, aktivitas pemakaian biogas meningkat terutama pada jam 08:00. Faktor lainnya, seperti kesalahan dalam pengukuran tekanan dengan menggunakan manometer.
Tabel 3 .

Properties $\mathrm{LFG}$ pada $1 \mathrm{~atm}$ dan $24{ }^{\circ} \mathrm{C}$

\begin{tabular}{ccc}
\hline \hline Properties & Unit & Value \\
\hline$M$ & & 30,025 \\
$S G$ & & 1,035 \\
$\rho$ & $\mathrm{kg} / \mathrm{m}^{3}$ & 1,260 \\
$\mu$ & $\mathrm{N} . \mathrm{s} / \mathrm{m}^{2}$ & $1,35 \times 10^{-5}$ \\
\hline
\end{tabular}

Error hasil perhitungan dan pengukuran tekanan di RK1, RK2, dan RK3.

\begin{tabular}{cccc}
\hline \hline Titik & $\begin{array}{c}\text { Hasil } \\
\text { Pengukuran } \\
(\mathbf{P a})\end{array}$ & $\begin{array}{c}\text { Hasil } \\
\text { Perhitungan } \\
(\mathbf{P a})\end{array}$ & $\begin{array}{c}\text { Error } \\
(\boldsymbol{\%})\end{array}$ \\
\hline RK1 & 106668,72222 & 106668,33284 & $-0,0004$ \\
RK2 & 106050,77778 & 106668,68911 & 0,5827 \\
RK3 & 104316,72222 & 106667,76888 & 2,2538 \\
\hline \hline
\end{tabular}

\section{Hasil Perhitungan Pressure Drop di Jaringan Pipa Existing}

Properties biogas ditunjukkan pada Tabel 3. Tekanan pada titik awal (0) didapatkan sebesar 106672,09382 Pa. RK1 adalah Rumah Kontrol 1 atau titik A1. RK2 adalah Rumah Kontrol 2 atau titik XIII2. RK adalah Rumah Kontrol 3 atau titik Y5. Hasil pengukuran dan perhitungan di RK1, RK2, dan RK3 menunjukkan error hasil perhitungan kurang dari $3 \%$, yang ditunjukkan pada Tabel 4.

Error ini termasuk kecil sehingga masih sesuai dengan keadaan di lapangan. Error hasil perhitungan terjadi karena tekanan di awal tidak diketahui. Padahal, tekanan pada titik sampel fluktuatif setiap jamnya tergantung dari penggunaan pelanggan biogas. Selain itu, fluida diasumsikan steady dan incrompressible. Pipa dan fitting seragam, serta bentuk sambungan rumah seragam. Padahal di lapangan berbeda terutama jenis pipa dan fitting, serta model sambungan rumah.

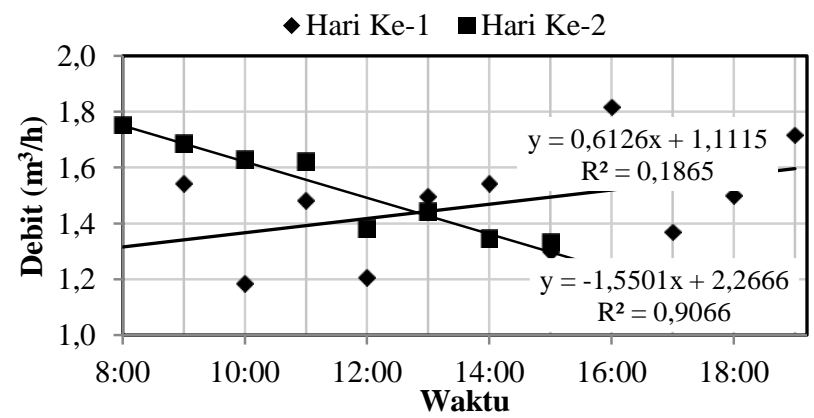

Gambar 2. Hasil pengukuran debit landfill gas pada hari pertama dan kedua dalam $\mathrm{m}^{3} / \mathrm{h}$.

\section{Penentuan Model Jaringan Pipa Future}

Pemilihan Desain jaringan pipa future dilakukan dengan mencari model dengan pressure drop terkecil pada branch XA, $\mathrm{XB}$, dan XC. Hasil perhitungan pressure drop pada branch $\mathrm{XA}, \mathrm{XB}$, dan $\mathrm{XC}$ sangat kecil yaitu kurang dari $1 \mathrm{~Pa}$. Hasil perhitungan jaringan pipa dengan delapan variasi model pada branch XA, XB, dan XC ditunjukkan oleh Gambar 4.

Pada branch XA, pressure drop terkecil dihasilkan model B1 sedangkan terbesar dihasilkan oleh model A3 yang 
ditunjukkan oleh Gambar 4a. Pada branch XB, pressure drop terkecil dihasilkan model sedangkan terbesar dihasilkan oleh model A4 yang ditunjukkan oleh Gambar 4b. Pada branch XC, pressure drop terkecil dihasilkan model A1 sedangkan terbesar dihasilkan oleh model A4 yang ditunjukkan oleh Gambar 4c. Model yang paling sesuai dan menghasilkan pressure drop terkecil yaitu model A1.

Faktor-faktor yang mempengaruhi pressure drop yaitu debit, panjang pipa, diameter pipa, dan fitting.

Pressure drop sebanding dengan debit. Pressure drop di XA sesuai dengan teori dimana pressure drop terkecil dimiliki oleh model A1 dan B1. Walaupun ada faktor lain selain debit yang mempengaruhi pressure drop di XA.

Pressure drop sebanding dengan panjang pipa. Pressure drop terkecil dihasilkan oleh model A1 dan B1. Padahal panjang pipa terkecil dimilki oleh model A3 dan B3. Sedangkan di XA sesuai dengan teori, pressure drop terkecil dihasilkan oleh model A1. Tetapi, model B2 menghasilkan pressure drop yang lebih kecil dibandingkan model A3 dan B3. Hal ini dikarenakan ada faktor lain yang mempengaruhi pressure drop di XB selain faktor panjang pipa.

Pressure drop sebanding dengan $\sum \mathrm{K} . \sum \mathrm{K}$ terkecil pada branch XA dan XB yaitu model A1. Sedangkan, $\sum$ K.terbesar pada branch XA dan XB yaitu model A3, B3, A4, dan B4. Sesuai dengan teori, pressure drop terkecil pada model A1 yang memiliki $\sum \mathrm{K}$ terkecil.

Dari penjelasan di atas didapatkan bahwa pressure drop di branch XA, XB, dan XC telah sesuai teori. Maka untuk mendapatkan pressure drop terkecil maka desain jaringan pipa future direkayasa sehingga debit kecil, panjang pipa pendek, dan tidak memiliki banyak fitting. model A1 telah memenuhi kriteria di atas. Secara teori mungkin model A1 adalah model terbaik, namun kenyataan di lapangan tidak sama. Banyak faktor yang harus dipertimbangan dalam pemasangan jaringan pipa pelanggan biogas. Topografi tanah yang menurun menyebabkan permasalahan penyumbatan aliran biogas oleh kondensat. Kondensat akan berkumpul di titik-titik yang lebih rendah. Penanggulangan permasalahan ini dapat dilakukan dengan memasang trap di beberapa titik sehingga kondensat mudah untuk dikeluarkan. Untuk memudahkan maintenance maka jaringan pipa ini harus mudah diakses.

\section{KESIMPULAN}

Berdasarkan permasalahan dan tujuan dari penelitian ini maka dapat disimpulkan sebagai berikut.

1. Tekanan tertinggi dihasilkan model A1. Hasil pengukuran pada RK1, RK2, dan RK3 yaitu 106668,72222 Pa; 106050,77778 $\mathrm{Pa}$; dan 104316,72222 $\mathrm{Pa}$. Hasil perhitungan jaringan pipa existing pada RK1, RK2, dan RK3 yaitu 106668,33284 Pa; 106668,68911 Pa; dan 106667,76888 Pa. Error hasil perhitungan kurang dari 3\% dan pressure drop kurang dari $2 \mathrm{kPa}$. Jaringan pipa existing telah memenuhi syarat yaitu tekanan gauge LFG ke kompor lebih dari $1 \mathrm{kPa}$ sehingga tidak diperlukan pembuatan desain yang baru.

2. Pressure drop pada setiap branch di jaringan pipa future kurang dari 1 Pa. Jaringan pipa future dengan model terbaik yaitu model A1. Tekanan yang dihasilkan model A1 tertinggi dibandingkan model lainnya kecuali pada branch XA. Model A2 menghasilkan tekanan lebih baik dibandingkan model A1 pada branch XA.

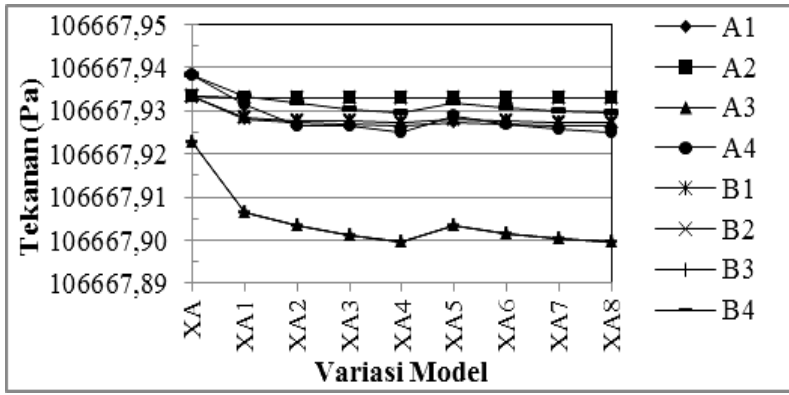

(a)

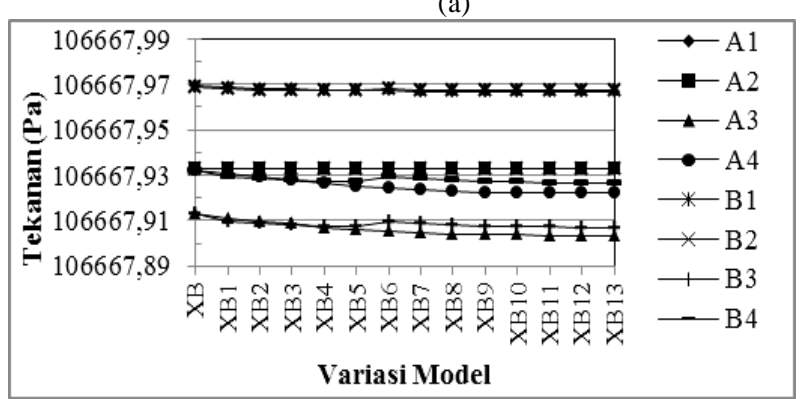

(b)

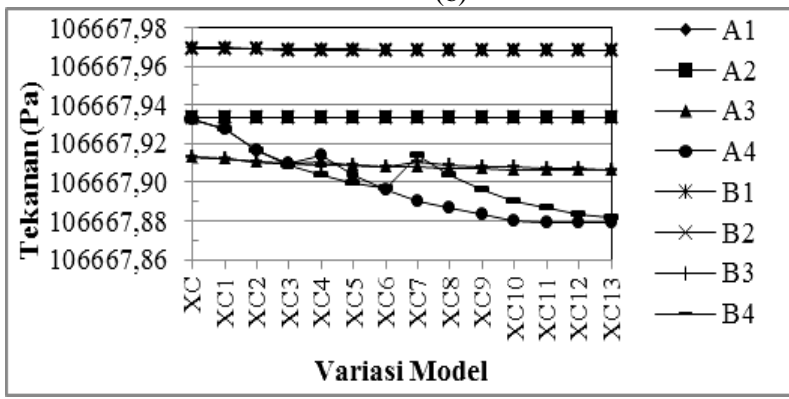

(c)

Gambar 4. Hasil perbandingan 8 variasi model pada (a) branch XA, (b) branch $\mathrm{XB}$, dan (c) branch $\mathrm{XC}$ dalam $\mathrm{Pa}$.

\section{DAFTAR PUSTAKA}

[1] S. Sukarni, "Exploring the potential of municipal solid waste (MSW) as solid fuel for energy generation: Case study in the Malang City, Indonesia," AIP Conf. Proc., vol. 1778, no. 1, p. 20003, 2016.

[2] R. Sumianto; A. S., Danar; Lukiawan, "Kebut uhan Standar dalam Mendukung Pengembangan Sumber Energi Baru (Biogas)," Standardisasi, vol. 15, no. 1, pp. 9-19, 2013.

[3] S. Darmawati, "Kinerja Penimbunan Sampah Sistem Semi Aerobik Lanfill sebagai Bahan Masukan Penyusunan Standar Landfill," Standardisasi, vol. 15, no. 1, pp. 28-35, 2013.

[4] DKP Kota Malang, "Sampah Sebagai Energi Baru Terbarukan," in Seminar Nasional Energi Terbarukan, 2014, pp. 1-39.

[5] Z. Septiropa, A. H. S. Fauzan, and M. Zainuddin, "Optimasi Sudut Ujung Pipa Penangkapan Gas Metana," J. Tek. Ind., vol. 12, no. 2, pp. 141-146, 2011. 
[6] A. Suko, C. Meidiana, and M. Anggraeni, "The Effect of Alternative Energy Utilization from Landfill on Methane Emission Reduction," KnE Energy, vol. 2, no. 2, pp. 30-36, 2015.

[7] C. Grima-Olmedo, A. Ramírez-Gómez, and R. AlcaldeCartagena, "Energetic performance of landfill and digester biogas in a domestic cooker," Appl. Energy, vol. 134, pp. 301308, 2014.

[8] U. Desideri, F. Di Maria, D. Leonardi, and S. Proietti, "Sanitary landfill energetic potential analysis: A real case study," Energy Convers. Manag., vol. 44, no. 12, pp. 1969-1981, 2003.

[9] S. E. Menon, Gas Pipeline Hydraulics, 1st ed. New York: CRC
Press, 2005.

[10] E. Durmusoglu, M. Y. Corapcioglu, and K. Tuncay, "Landfill settlement with decomposition and gas generation," J. Environ. Eng., vol. 131, no. 9, pp. 1311-1321, 2005.

[11] M. Lestari, Letisa Indah; Soemirat, Juli; Dirgawati, "Penentuan Konsentrasi Gas Metan di Udara Zona 4 TPA Sumur Batu Kota Bekasi," Reka Lingkung., vol. 1, no. 1, pp. 1-11, 2013.

[12] A. P. Munson, Bruce R.; Okiishi, Theodore H.; Huebsch, Wade W.; Rothmayer, Fundamentals of Fluid Mechanics, 7th ed. United States of America: John Wiley \& Sons, Inc., 2013.

[13] Wavin, "Panduan Teknik dan Katalog Produk.” pp. 2-10. 